УДК 622.272/.275.34;504.05/06:622.34

\title{
БЕСЦЕМЕНТНЫЕ ЗАКЛАДОЧНЫЕ СМЕСИ НА ОСНОВЕ ВОДОРАСТВОРИМЫХ ТЕХНОГЕННЫХ ОТХОДОВ
}

\author{
Хайрутдинов Марат Минизяетович1, \\ profmarat@gmail.com
}

\section{Конгар-Сюрюн Чейнеш Буяновна ${ }^{1}$,} Cheynesh95@mail.ru

Тюляева Юлия Сергеевна ${ }^{1}$, tyulyaevayu@gmail.com

\author{
Хайрутдинов Альберт М'1, \\ khayrutdinov.albert99@gmail.com \\ 1 Национальный исследовательский технологический университет «МИСиС», \\ Россия, 119991, г. Москва, Ленинский проспект, 4.
}

\begin{abstract}
Актуальность исследования обусловлена увеличением воздействия деятельности горно-обогатительных и металлургических предприятий на экологию. Приоритетным направлением является создание и применение щадящих геотехнологий, снижающих уровень влияния горно-обогатительного производства на экосистему. С каждым годом происходит интенсисрикация образования отходов горного, обогатительного и металлургического производств, что приводит к увеличению объемов техногенных массивов. Данный фракт предопределяет необходимость их утилизации. Использование техногенных отходов водорастворимых руд для замены специально добываемого инертного компонента при приготовлении закладочного композита, а замена цементного вяжущего на отходы магниевого и содового производств или шлаки металлургических заводов, содержащих $\mathrm{MgO}$, представляется хорошим способом их утилизации.

Цель работы: создание бесцементной закладочной смеси с улучшенными прочностными и заданными реологическими свойствами на основе активированных техногенных отходов водорастворимых руд при использовании в качестве вяжущего магнийсодержащие шлаки металлургического завода, что позволит реализовать принцип безотходного производства.

Объект: закладочная смесь на основе активированных текущих галитовых отходов галургического способа обогащения ПАО «Уралкалий» (инертньй заполнитель) и магнийсодержащих шлаков Чусовского металлургического завода (вяжущее), с применением лигносульфоната для улучшения связующей способности и в качестве регулятора реологических свойств.

Методология: применялись актуальные государственные стандарты и утверждённая методика исследований; испытания производились на тарированном и исправном оборудовании; активирование производилось в лабораторном дезинтеграторе DESI-11; образцы на сжатие тестировались на испытательном прессе ПИ-2000-A; реологические свойства закладочной смеси исследовались по осадке конуса «СтройЦНИЛа» и растекаемости на вискозиметре Суттарда; достоверность подтверждается повторяемостью результатов при достаточном количестве экспериментов.

Результаты. Обоснована допустимость замены цементного вяжущего на магнийсодержащие отходы (шлаки Чусовского металлургического завода). Доказана возможность применения техногенных отходов водорастворимых руд для замены специально добываемого инертного компонента при приготовлении закладочного композита. Приведены результаты исследований замены специально добываемого инертного заполнителя техногенными отходами. Исследовано положительное влияние механической активационной обработки компонентов закладочной смеси на её реологические свойства и прочностные характеристики закладочного массива. Подтверждено применение лингосульфоната в качестве добавки, позволяющей улучшить связующие и реологические свойства закладочной смеси.
\end{abstract}

\section{Ключевые слова:}

Безотходное производство, водорастворимые руды, геотехнология, закладка выработанного пространства, закладочная смесь, отходы горного производства, техногенные отходы, хвосты обогащения.

\section{Введение}

Из ранее проведённых исследований следует, что на российскую горнодобывающую отрасль приходится около $5 \%$ мирового производства железной руды [1], порядка 25 \% калийных руд, а всего Россия производит 9,5 \% мировой продукции добываемого сырья [2]. Однако в отличие от большинства стран Европы и Японии, обеспечивающих высокий уровень экологической безопасности, Российская горная промышленность находится на достаточно низком уровне защиты окружающей среды, утилизации или переработки техногенных отходов горно-обогатительного и металлургического секторов и использования их в последующем производстве [2, 3]. С каждым годом содержание по- лезного компонента в добываемой руде уменьшается, что приводит к большему образованию отходов после её переработки. Накопление техногенных отходов является одной из форм воздействия человека на экосистему, что ведёт к различным качественным или количественным изменениям её элементов [4].

При получении 1 т калийных удобрений образуется до 30 т водорастворимых хвостов обогащения, на удаление и хранение которых затрачивается в среднем от 5 до $8 \%$ стоимости производимой продукции. Но если признать, что срок существования хвостохранилищ и отвалов неограничен, то мультипликативный ущерб от размещения и хранения техногенных отходов может превосходить ценность добытого 
продукта. На сегодняшний день в цикличном производстве используется не более 10 \% извлекаемых пород от вскрышных и проходческих работ и примерно $20 \%$ водорастворимых техногенных отходов обогащения. По сведениям Министерства природных ресурсов и экологии к настоящему времени на территории России складировано более 45 млрд т отходов горно-обогатительного производства различного класса опасности. В России ежегодно увеличивается уровень загрязнения техногенными отходами. За последнее двадцать лет годовой объём прироста техногенных массивов пустыми породами от проходческих и вскрышных работ увеличился на 30 \% и составляет 210 млн м ${ }^{3} /$ год, а отходов обогатительных фабрик 140 млн м/год [5]. Все эти объёмы загрязняют окружающую среду, выводят из оборота плодородные земли, занимая тысячи гектар сельскохозяйственных угодий.

Применение техногенных отходов водорастворимых руд в закладочных композитах

Идея применения отходов обогатительного и металлургического переделов для замены инертного компонента при создании закладочного композита не является новой [3, 6-8]. Использование водорастворимых отходов, образующихся в результате обогащения, для создания композитных смесей позволит утилизировать техногенные отходы, что значительно снизит воздействие горного сектора на экосистему региона [9]. Из анализа мировой практики добычи полезного ископаемого следует, что 35 \% горнодобывающих предприятий отдают предпочтение системам с искусственным поддержанием очистного пространства, а именно, системам с твердеющей закладкой [6] Отработка месторождения геотехнологией с закладкой улучшает качественно-количественные показатели извлечения [10], увеличивает безопасность на участках производства горных работ, в частности и извлечения полезного ископаемого в целом [11], снижает риски возникновения техногенных аварий на предприятиях горнопромышленного сектора $[6,8]$ Техногенные катастрофы на горных предприятиях: провалы; горные удары и техногенные землетрясения, зачастую сопровождаются сейсмической активностью и вибрационными колебаниями. Влияние вибрационных колебаний на подземные выработки и поверхностные сооружения широко обсуждались в ранее проведённых исследованиях [12-16].

При создании закладочного композита в качестве вяжущего используют цемент или его производные, а в качестве инертного компонента - специально добываемые материалы: песок, гравий, щебень. Техноген- ные отходы горного и обогатительного производств широко используются на предприятиях горного сектора всего мира. Порядка 100 рудников Австралии, Ирландии, Канады, России, США, Финляндии, Швеции, Японии и других применяют техногенные отходы. При этом общегодовой объём извлечения ископаемых в этих странах составляет около 64 млн т. Доля использования техногенных отходов горного сектора для замены специально добываемого инертного компонента распределяется следующим образом: $67 \%$ отходы обогатительных фабрик, $25 \%$ - пустая порода от вскрышных и проходческих работ, 7 \% - пески и шлаки металлургического передела или ТЭЦ [17].

В отходах обогатительных фабрик и металлургических заводов, хотя и не в значительном количестве, остаются полезные компоненты, которые можно извлечь при повторной глубокой переработке (табл. 1). Зачастую в техногенных отходах горно-обогатительного и металлургического секторов имеются вредные примеси. Всё это существенно ограничивает возможность применения техногенных отходов в цикличном производстве. Идея применения техногенных отходов водорастворимых руд при приготовлении композитного материала, используемого для закладки выработанного пространства, не является новой [18-23]. Ранее проводимые исследования активационной обработки техногенных отходов обогатительных фабрик полиметаллических руд показали положительные результаты $[7,8,17,24]$. Но применение в качестве инертного компонента водорастворимых техногенных отходов обогатительных фабрик производилось без дополнительной активационной переработки.

Кроме того, смеси, используемые для закладочных работ при извлечении минерального сырья, отличаются от смесей, растворов и бетонов, предназначенных для гражданского строительства, увеличенным количеством воды. Повышенное отношение воды к твёрдой составляющей в закладочных композитах необходимо для улучшения её транспортной способности до места укладки и растекаемости в закладываемой камере. Увеличенное содержание воды приводит к снижению прочностных характеристик создаваемого искусственного массива [24].

В связи с этим целью настоящего исследования являлось создание композитного материала на основе водорастворимых техногенных отходов галлургического способа обогащения с заданными реологическим свойствами и предназначенного для формирования искусственного массива с повышенными прочностными характеристиками.

Таблица 1. Химический состав техногенных отходов обогащения водорастворимых руд

Table 1. Chemical composition of manmade enrichment waste of water-soluble ore

\begin{tabular}{|c|c|c|c|c|c|c|c|c|c|}
\hline \multicolumn{2}{|c|}{$\begin{array}{l}\text { Отходы обогащения } \\
\text { Enrichment waste }\end{array}$} & $\begin{array}{c}\text { Компоненты } \\
\text { Components }\end{array}$ & $\mathrm{KCl}$ & $\mathrm{NaCl}$ & $\mathrm{MgCl}_{2}$ & $\mathrm{CaSO}_{4}$ & $\begin{array}{l}\text { Нерастворимый остаток } \\
\text { Insoluble residue }\end{array}$ & $\mathrm{Br}^{-}$ & $\begin{array}{l}\mathrm{H}_{2} \mathrm{O}_{\text {крист. }} \\
\mathrm{H}_{2} \mathrm{O}_{\text {cryst. }}\end{array}$ \\
\hline \multirow{2}{*}{\begin{tabular}{|l} 
Галургические \\
Halurgic \\
\end{tabular}} & Лежалые/Stale & \multirow{4}{*}{$\begin{array}{c}\text { Массовая } \\
\text { доля, \% } \\
\text { Weight } \\
\text { ratio, \% }\end{array}$} & 3,35 & 92,66 & 0,07 & 1,91 & 1,9 & 0,03 & 0,08 \\
\hline & Текуи & & 1,91 & 94,3 & 0,07 & 1,914 & 1,7 & 0,026 & 0,08 \\
\hline Флотационные & Лежалые/Stale & & 9,96 & 82,64 & 1,1 & 4,488 & 1,7 & 0,032 & 0,08 \\
\hline Flotation & Текущие/Current & & 4,88 & 87,78 & 1,1 & 4,331 & 1,8 & 0,029 & 0,08 \\
\hline
\end{tabular}


В качестве инертного компонента применяются техногенные водорастворимые отходы обогатительной фабрики, прошедшие дополнительную активаци- онную обработку. Химический и гранулометрический составы отходов обогатительной фабрики водорастворимых руд приведены в табл. 1,2 .

Таблица 2. Гранулометрический состав техногенных отходов обогащения водорастворимых руд

Table 2. Granulometric composition of manmade enrichment waste of water-soluble ore

\begin{tabular}{|c|c|c|c|c|c|c|c|c|c|}
\hline \multirow{2}{*}{$\begin{array}{c}\text { Отходы } \\
\text { Waste }\end{array}$} & \multicolumn{7}{|c|}{ Крупность частиц, мм/Particle size, mm } & \multicolumn{2}{c|}{ Средняя крупность } \\
\cline { 2 - 11 } & +7 & $7 \ldots 5$ & $5 \ldots 3$ & $3 \ldots 2$ & $2 \ldots 1$ & $1 \ldots 0,5$ & $0,5 \ldots 0,25$ & $-0,25$ & Average size \\
\cline { 2 - 10 } & 7,4 & 7,3 & 17 & 16,3 & 20,9 & 19,5 & 8,6 & 3,0 & 2,54 \\
\hline
\end{tabular}

Принимая во внимание ранее накопленный опыт в горнодобывающей индустрии, необходимо учесть, что при создании композита для закладки выработанного пространства на основе техногенных отходов водорастворимых руд в качестве вяжущих используются следующие материалы: цемент, известь, доменные гранулированные шлаки металлургического передела, золошлаковые отходы ТЭЦ и ГРЭС, добавки из гипса и хлористого кальция. Помимо этого, фундаментальным материалом для приготовления твердеющего закладочного композита могут служить: бишофит, магнезиальный цемент, каустический магнезит, керамзит.

Научно-изыскательские работы, проведенные ранее в области создания твердеющих закладочных смесей на основе отходов водорастворимых руд, продемонстрировали преимущество магнезиальных вяжущих $[9,22]$.

\section{Создание искусственного массива на основе техногенных отходов водорастворимых руд}

Ранее проведёнными исследованиями установлено, что в качестве затворителя наиболее эффективно использовать солевые растворы ввиду того, что скорость твердения и прочностные характеристики массива резко увеличиваются [17-19]. Дополнительным преимуществом магнезиального вяжущего является его способность в малых количествах образовывать достаточно прочные связи для большой массы инертного заполнителя, в данном случае техногенных отходов водорастворимых руд [18-20]. Для промышленного производства в качестве вяжущего не обязательно использовать специально приготовленный магнезиальный цемент или каустический магнезит. Для уменьшения себестоимости закладочных работ можно использовать отходы магниевого и содового производств или магнийсодержащие шлаки металлургических заводов, что представляет особый интерес, учитывая значительные объемы закладочных работ $[18,22]$.

Пониженную способность омоноличивания можно компенсировать применением цемента или активирующей добавки. При проведении экспериментов в данной работе применялись магнийсодержащие шлаки Чусовского металлургического завода.

Все эксперименты выполнялись в соответствии с методическими указаниями и инструкцией по контролю качества закладочных смесей [25].

Магнезиальные шлаки и техногенные отходы обогащения водорастворимых руд в закладочную смесь добавлялись в пропорции 25 и 51 \% от общего объёма соответственно. При этом производилась раздельная активация компонентов в дезинтеграторе DESI11путём измельчения до содержания класса менее 0,071 мм не менее 68-72 и 88-92 \% каждого компонента соответственно.

Подвижность, расслаиваемость и растекаемость закладочного композита исследовали по стандартной методике «СтройЦНИЛа» по глубине осадки конуса и на вискозиметре Суттарда.

Затвердевание образцов происходило в условиях, предусмотренных методикой $\left(\mathrm{T}=20 \pm 2{ }^{\circ} \mathrm{C} ; \mathrm{W}=95 \pm 5 \%\right)$, их испытание на сжатие производили через заданные сроки, предусмотренные методикой: 7; 28; 60 и 90 суток [25].

Испытания первого состава показали неудовлетворительные результаты, что выразилось в низких прочностных характеристиках образцов и малой подвижности композита (состав № 1 в табл. 3).

С целью увеличить гидравлическую активность магнезиальный шлак обрабатывали до крупности не менее 88-92 \% класса менее 0,071 мм. Крупность отходов обогащения водорастворимых руд оставляли без изменения. При испытании образцов на одноосное сжатие было заметное увеличение показателей. Но при этом необходимо констатировать, что реологические свойства закладочной смеси не удовлетворяли показателям транспортабельности к месту укладки (состав № 2 в табл. 3).

Для улучшения реологических свойств и увеличения растекаемости закладочной смеси попытались снизить долю фракции менее 0,071 мм в техногенных отходах обогащения водорастворимых руд. Данный эксперимент привёл к падению прочности образцов при испытании на одноосное сжатие (состав № 3 в табл. 3).

Увеличение водотвёрдого отношения для улучшения реологических свойств является нецелесообразным ввиду резкого падения прочностных характеристик закладочного массива и наращивания объёмов водоотлива.

Ранее проведённые исследования показали перспективность применения химических добавок при создании материалов с более прочными структурными связями [26], что позволяет увеличить прочностные характеристики создаваемого искусственного массива [17, 22]. К активирующим добавкам, способным не только повысить прочностные характеристики закладочного массива, но и увеличить транспортабельность закладочной смеси, относится лингосульфонат $[18,27]$, полученный путем переработки отработанных сульфитных и бисульфитных щелоков. 
Таблица 3. Результаты испытаний закладочных смесей

Table 3. Test results of backfill mixtures

\begin{tabular}{|c|c|c|c|c|c|c|c|c|c|c|c|c|}
\hline \multirow{4}{*}{$\begin{array}{l}\text { № } \Pi / \Pi \\
\text { No }\end{array}$} & \multicolumn{6}{|c|}{$\begin{array}{c}\text { Компоненты закладочной смеси } \\
\text { Backfill mixture components }\end{array}$} & \multirow{4}{*}{ 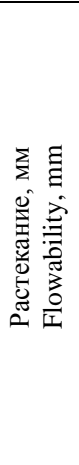 } & \multirow{4}{*}{ 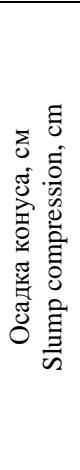 } & \multirow{2}{*}{\multicolumn{4}{|c|}{$\begin{array}{c}\text { Предел прочности при одноосном } \\
\text { сжатии, МПА } \\
\text { Ultimate uniaxial compression strength, } \\
\text { MPa }\end{array}$}} \\
\hline & \multicolumn{2}{|c|}{$\begin{array}{c}\text { Магнезиальный шлак } \\
\text { Magnesian slags }\end{array}$} & \multicolumn{2}{|c|}{$\begin{array}{c}\text { Отходы обогащения } \\
\text { водорастворимых руд } \\
\text { Enrichment waste of } \\
\text { water-soluble ores }\end{array}$} & \multirow{3}{*}{ 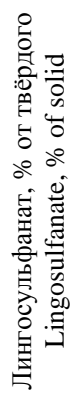 } & \multirow{3}{*}{ 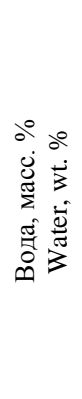 } & & & & & & \\
\hline & \multirow[b]{2}{*}{ 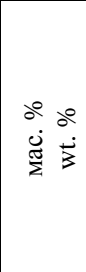 } & \multirow{2}{*}{ 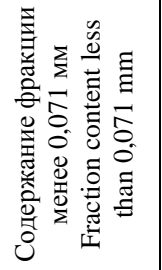 } & \multirow[b]{2}{*}{ 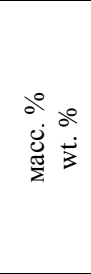 } & \multirow{2}{*}{ 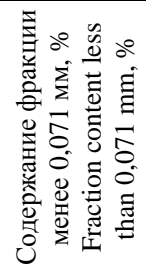 } & & & & & \multicolumn{4}{|c|}{$\begin{array}{l}\text { Продолжительность твердения, сутки } \\
\text { Duration of mixture hardening, days }\end{array}$} \\
\hline & & & & & & & & & 7 & 28 & 60 & 90 \\
\hline 1 & 25,0 & $68-72$ & 51,0 & $88-92$ & - & 24,0 & 105 & 10 & 0,2 & 1,5 & 1,9 & 2,2 \\
\hline 2 & 25,0 & $88-92$ & 51,0 & $88-92$ & - & 24,0 & 95 & 10 & 0,15 & 1,6 & 2,2 & 2,5 \\
\hline 3 & 25,0 & $88-92$ & 51,0 & $68-72$ & - & 24,0 & 120 & 14 & 0,1 & 1,2 & 1,7 & 1,8 \\
\hline 4 & 25,0 & $88-92$ & 51,0 & $88-92$ & 1 & 23,25 & 165 & 16 & 0,25 & 2,0 & 2,75 & 3,1 \\
\hline
\end{tabular}

Применение лингосульфаната позволило получить закладочный массив с повышенной прочностью при реологических характеристиках, удовлетворяющих требованиям транспортабельности (№ 4 в табл. 2).

При создании искусственного массива на основе техногенных отходов необходимо учитывать длительное влияние компонентов закладки на омоноличенный массив и достаточно строго подходить к их применению. Все процессы, способные возникнуть в искусственном массиве после затвердевания закладочной смеси, практически невозможно предугадать и смоделировать. Достаточно полно и всецело методы и способы контроля омоноличенного массива рассмотрены в работах $[28,29]$.

Применение техногенных отходов при приготовлении композитного материала, предназначенного для поддержания очистного пространства, без дополнительной переработки противоречит экономической целесообразности и экологической безопасности. Разработаны технологии извлечения полезных компонентов из техногенных отходов [30].

С развитием науки, техники и технологии улучшаются качественные показатели обогащения, что подтверждает анализ химического состава хвостов обогащения, взятых с хвостохранилищ (до 2000 г. формирования) и непосредственно с производственной линии обогащения (табл. 1) на предприятии ПАО «Уралкалий».

Следовательно, для закладочных работ без дополнительной переработки можно использовать текущие хвосты галургического способа обогащения. При использовании лежалых хвостов галургического способа обогащения и хвостов флотационного способа обогащения необходимо произвести их дополнительное обогащение. Дополнительное обогащение можно производить на мощностях обогатительной фабрики, освободившихся в результате уменьшения объёмов добычи предприятия ввиду выхода из эксплуатации БКРП-1 «Уралкалий».

\section{Заключение}

Применение бесцементной технологии для создания искусственного массива на основе водорастворимых техногенных отходов позволяет разработать закладочный массив с необходимыми прочностными характеристиками. Применение отходов горного и промышленного производства для создания композитного материала ведёт к их утилизации, исключает применение специально добываемого сырья для компонентов смеси, что приводит к снижению расходов на закладочные работы, а как следствие уменьшает стоимость добываемой руды. Разработка закладочной смеси из техногенных отходов создаёт возможность реализовать принцип организации горного производства, предусматривающий применение промежуточных продуктов в цикличном производстве и исключающий образование техногенных отходов водорастворимых руд.

Образование и складирование техногенных отходов водорастворимых руд создаёт глобальную экологическую проблему, влекущую изменение ландшафтов в районах горного производства и ухудшение состояния окружающей среды. Создание безотходного горного производства с применением промежуточных продуктов в цикличном производстве позволяет сохранить экологию региона. Применение техногенных отходов водорастворимых руд в цикличном производстве приведёт в последствии к мультипликационному экономическому эффекту, определяемому суммой величин предотвращаемого экологического ущерба, затрат на складирование и хранение, расходов на утилизацию и экологические отчисления.

Использование техногенных отходов водорастворимых руд не будет иметь положительный экономический эффект без их повторной переработки и производства продукции. При этом вовлечение в переработку техногенных отходов водорастворимых руд создаёт предпосылки создания новой материально-сырьевой базы горнопромышленного комплекса и исключает расходы на разведку и освоение новых месторождений. 


\section{СПИСОК ЛИТЕРАТУРЫ}

1. Самарина В.П. Горнодобывающая промышленность России на мировом рынке: Современные тенденции // Горный информационно-аналитический бюллетень. - 2017. - № 3. - С. 209-216.

2. Пучков Л.А. Россия в горнодобывающем мире // Горный информационно-аналитический бюллетень. - 2005. - № 5. - С. 5-10.

3. Использование хвостов обогащения руд в твердеющих смесях / В.И. Голик, Ю.В. Дмитрак, Р.Н. Максимов, Ю.М. Ляшенко // Горный информационно-аналитический бюллетень. - 2018. № S25. - C. 18-27.

4. The reuse of mining and construction waste for backfill as one of the sustainable activities / A.L. Ivannikov, Ch. Kongar-Syuryun, J. Rybak, Y. Tyulyaeva // World Multidisciplinary Earth Sciences Symposium (WMESS 2019). - Prague: IOP Conference Series: Earth and Environmental Science, 2019. - V. 362. - 012130. DOI: 10.1088/1755-1315/362/1/012130.

5. Чантурия В.А., Вигдергауз В.Е. Инновационные технологии переработки техногенного минерального сырья // Горный журнал. - 2008. - № 6. - С. 71-74.

6. Влияние хвостохранилищ на окружающую среду горнодобывающего региона / В.И. Голик, Ю.В. Дмитрак, В.С. Сергеев, В.В. Вернигор // Экология и промышленность России. 2018. - T. 22. - № 6. - С. 44-48.

7. Использование хвостов обогащения в приготовлении твердеющих закладочных смесей / В.И. Голик, Ю.В. Дмитрак., Ч. Чан, С.А. Масленников // Известия Уральского государственного горного университета. - 2018. - № 2 (50). - С. 95-101. DOI: 10.21440/2307-2091-2018-2-95-101

8. Голик В.И., Разоренов Ю.И., Масленников С.А. Охрана природной геологической среды утилизацией хвостов обогащения руд // Известия Томского политехнического университета. Инжиринг георесурсов. - 2015. - Т. 326. - № 6. - С. 6-15.

9. Industrial waste in concrete mixtures for construction of underground structures and minerals extraction / Ch. KongarSyuryun, Y. Tyulyaeva, A. Khairutdinov, T. Kowalik // Construction the Formation of Living Environment (FORM-2020). Hanoi: IOP Conference Series: Materials Science and Engineering, 2020. - V. 869. - 032004. DOI: 10.1088/1757899X/869/3/032004.

10. Технологические схемы отработки камерами с расширением и закладкой выработанных пространств / В.И. Сарычев, В.В. Мельник, М.А. Голодов, И.Н. Зубаков, С.С. Жуков // Известия Тульского государственного университета. Науки о Земле. - 2011. - № 2. - С. 203-206.

11. Голик В.И., Бурдзиева О.Г. Повышение безопасности труда увеличением области применения твердеющих смесей из отходов переработки // Безопасность труда в промышленности. - 2016. - № 8. - С. 51-54.

12. The surface wave attenuation as the effect of vibratory compaction of building embankments / A. Herbut, M.M. Khairutdinov, C. Kongar-Syuryun, J. Rybak // World Multidisciplinary Earth Sciences Symposium (WMESS 2019). - Prague: IOP Conference Series: Earth and Environmental Science, 2019. - V. 362. 012131. DOI: 10.1088/1755-1315/362/1/012131.

13. Dobrzycki P., Kongar-Syuryun Ch., Khairutdinov A. Vibration reduction techniques for Rapid Impulse Compaction (RIC) // Modelling and Methods of Structural Analysis. - Moscow: IOP Conference Series: Journal of Physics, 2019. - V. 1425. - 012202 DOI:10.1088/1742-6596/1425/1/01220.

14. Herbut A., Rybak J., Brzakała W. On a sensor placement methodology for monitoring the vibrations of horizontally excited ground // Sensors. - 2020. - V. 20 (7). - 1938. DOI $10.3390 / \mathrm{s} 20071938$
15. Wyjadłowski M. Methodology of dynamic monitoring of structures in the vicinity of hydrotechnical works - selected case studies // Studia Geotechnica et Mechanica. - 2017. - V. 39. № 4. - P. 121-129. DOI: 10.1515/sgem-2017-0042.

16. Herbut A., Rybak J. Guidelines and recommendations for vibration control in the case of rapid impulse compaction // Advances and trends in engineering sciences and technologies II. High Tatras: CRC Press, Taylor \& Francis Group, 2017. - P. 761-766. DOI: $10.1201 / 9781315393827-129$

17. Ермолович Е.А. Бесцементная закладочная смесь на основе техногенных отходов // Научные ведомости Белгородского государственного университета. Серия: Естественные науки. 2010. - № 9 (80). - C. 156-158.

18. Вотяков М.В. Повышение полноты извлечения запасов калийных руд на основе закладки выработанного пространства галитовых отходов: дис. ... канд. техн. наук. - М., 2009. - 89 с.

19. Гаркушин П.К. Исследование и выбор составов твердеющей закладки для калийных рудников Прикарпатья: дис. ... канд. тех. наук. - Л., 1972. - 179 с.

20. Кравченко Ю.Г. Разработка составов твердеющих закладочных смесей из отходов переработки руд калийных предприятий: дис. ... канд. тех. наук. - Пермь, 1985. - 122 с.

21. Pengqiang Sh., Xianxiao X., Boyun L. Discussion on the main potash-concentrated districts and the resource potential in China // Geology of Chemical Minerals. - 2011. - V. 33. - № 1. - P. 1-8.

22. Хайрутдинов М.М., Вотяков М.В. Выбор химических добавок для твердеющей закладки на калийных рудниках // Горный информационно-аналитический бюллетень. - 2007. - № 6. C. 218-221

23. Selected black-coal mine waste dumps in the Ostrava Karviná region: an analysis of their potential use / D. Niemiec, M. Duraj, X. Cheng, M. Marschalko, J. Kubáč // World Multidisciplinary Earth Sciences Symposium (WMESS 2017). - Prague: IOP Conference Series: Earth and Environmental Science, 2017. V. 95. - 042061. DOI: 10.1088/1755-1315/95/4/042061.

24. Ермолович Е.А., Ермолович О.В. Исследования реологических характеристик закладочной гидросмеси отходов обогащения железистых кварцитов ОАО «Комбинат КМАРУДА» // Научные ведомости Белгородского государственного университета. Серия: Естественные науки. - 2015. - № 9 (206). C. $143-146$

25. Методические рекомендации по контролю качества закладочных смесей / под ред. Н.Н. Мельников. - М.: Горный институт Кольского научного центра РАН, 1990. - 94 c.

26. Brzakała W. Strength modelling of geomaterials with random systems of structural joints // Probabilistic Engineering Mechanics. - 2011. - V. 26. - № 2. - P. 321-330.

27. Вотяков М.В. Формирование высокопрочного закладочного массива при использовании в качестве активатора лигносульфоната // Горный информационно-аналитический бюллетень. - 2008. - № 10. - С. 199-203.

28. Gorska K., Muszyński Z., Rybak J. Displacement monitoring and sensitivity analysis in the observational method // Studia Geotechnica et Mechanica. - 2013. - V. 35 - № 3. - P. 25-43.

29. Bauer J., Puła W., Wyjadłowski M. Effect of partial mining of shaft protection pillar in terms of reliability index // Georisk. 2015. - V. 9. - № 4. - P. 242-249.

30. Механохимическая технология добычи металлов из хвостов обогащения / В.И. Голик, Ю.И. Разоренов, В.С. Бригида, О.Г. Бурдзиева // Известия Томского политехнического университета. Инжиниринг георесурсов. - 2020. - Т. 331. - № 6. C. $175-183$.

Поступила 22.09.2020 2.

\section{Информация об авторах}

Хайрутдинов М.M., кандидат технических наук, доцент кафедры геотехнологии Горного института, Национальный исследовательский технологический университет «МИСиС».

Конгар-Сюрюн Ч.Б., студент, Национальный исследовательский технологический университет «МИСиС».

Тюляева Ю.С., студент, Национальный исследовательский технологический университет «МИСиС».

Хайрутдинов А., студент, Национальный исследовательский технологический университет «МИСиС». 
UDC 622.272/.275.34;504.05/06:622.34

\title{
CEMENTLESS BACKFILL MIXTURES BASED ON WATER-SOLUBLE MANMADE WASTE
}

\author{
Marat M. Khayrutdinov ${ }^{1}$, \\ profmarat@gmail.com
}

\section{Cheynesh B. Kongar-Syuryun ${ }^{1}$,} Cheynesh95@mail.ru

Yulia S. Tyulyaeva ${ }^{1}$, tyulyaevayu@gmail.com

\author{
Albert M Khayrutdinov' \\ khayrutdinov.albert99@gmail.com \\ 1 National University of Science and Technology MISIS, \\ 4, Leninsky avenue, Moscow, 119991, Russia.
}

The relevance of the research is caused by the increasing the impact of mining processing and metallurgical enterprises on the environment. The priority area is the creation and application of sparing geotechnologies that reduce the level of impact of mining and processing production on the ecosystem. The intensification of waste generation from mining, processing and metallurgical industries occurs every year. This leads to an increase in formation of manmade mass. This fact determines the need for their disposal. A good way of disposal is the use of manmade waste of water-soluble ores as an inert filler for preparing a backfill mixture, and to replace the cement binder with magnesium and soda production waste or metallurgical plant slags containing MgO.

The main aim of the research is to create a cementless backfill mixture with improved strength and specified rheological properties based on activated manmade waste of water-soluble ores when using magnesium-containing slags of a metallurgical plant as a binder. This will allow implementing the principle of non-waste production.

Object: backfill mixture based on activated current halite waste of the galurgic enrichment method of PJSC «Uralkali» (inert aggregate) and magnesium-containing slags of the Chusovsky metallurgical plant (binder), using lignosulfonate to improve the binding capacity and as a regulator of rheological properties.

Methodology: the current State standards and approved research methods were applied; tests were performed on calibrated and serviceable equipment; activation was carried out in a laboratory disintegrator DESI-11, samples for compression were tested on a test press PI-2000-A; the rheological properties of the backfill mixture were studied by the slump compression "StroyTSNIL» and by the flowability on a Suttard viscometer; reliability is confirmed by the repeatability of results with a sufficient number of experiments.

Results. The permissibility of replacing the cement binder with magnesium-containing waste (slags of the Chusovsky metallurgical plant) is proved. The possibility of using manmade waste of water-soluble ores to replace a specially extracted inert component in the preparation of a backfill mixture was proved. The results of the research on replacing a specially mined inert filler with technogenic waste are presented. The positive effect of mechanical activation treatment of the backfill mixture components on its rheological properties and strength characteristics of the fill mass was investigated. The use of lingosulfonate was confirmed as an additive that improves the binding and rheological properties of the backfill mixture.

\section{Key words:}

Non-waste production, water-soluble ores, geotechnology, backfill of mined-out void, backfill mixture, mining waste, manmade waste, enrichment tails.

\section{REFERENCES}

1. Samarina V.P. Mineral resource industry of Russia in the world market: current developments. Mining Information and Analytical Bulletin, 2017, no. 3, pp. 209-216. In Rus.

2. Puchkov L.A. Rossiya v gorno-dobyvayushchem mire [Russia in the mining world]. Mining Information and Analytical Bulletin, 2005 , no. 5, pp. 5-10.

3. Golik V.I., Dmitrak Yu.V., Maksimov R.N., Lyashenko Yu.M. The use of tailings of the ores in hardening mixtures. Mining Information and Analytical Bulletin, 2018, no. S25, pp. 18-27. In Rus.

4. Ivannikov A.L., Kongar-Syuryun Ch., Rybak J., Tyulyaeva Y. The reuse of mining and construction waste for backfill as one of the sustainable activities. World Multidisciplinary Earth Sciences Symposium (WMESS 2019). Prague, IOP Conference Series: Earth and Environmental Science, 2019. Vol. 362, 012130. DOI: $10.1088 / 1755-1315 / 362 / 1 / 012130$

5. Chanturiya V.A., Vigdergauz V.E. Innovative technologies for processing of man-caused mineral raw materials. Gornyi Zhurnal, 2008, no. 6, pp. 71-74. In Rus.

6. Golik V., Dmytrak Y., Sergeev V., Vernigor V. Impact of tailing dumps on the environment of the mining region. Ecology and Industry of Russia, 2018, vol. 22, no. 6, pp. 44-48. In Rus.
7. Golik V.I., Dmytrak Y.V., Chan Ch., Maslennikov S.A. The use of tailings while preparing hardening filling mixtures. News of the Ural State Mining University, 2018, no. 2 (50), pp. 95-101. In Rus. DOI: 10.21440/2307-2091-2018-2-95-101.

8. Golik V.I., Razorenov Yu.I., Maslennikov S.A. Protection of natural geological environment by utilizing ore tailings. Bulletin of the Tomsk Polytechnic University. Geo Assets Engineering, 2015, vol. 326, no. 6, pp. 6-15. In Rus.

9. Kongar-Syuryun Ch., Tyulyaeva Y., Khairutdinov A., Kowalik T. Industrial waste in concrete mixtures for construction of underground structures and minerals extraction. Construction the Formation of Living Environment (FORM-2020). Hanoi, IOP Conference Series: Materials Science and Engineering, 2020. Vol. 869, 032004, DOI: $10.1088 / 1757-899 X / 869 / 3 / 032004$.

10. Sarychev V.I., Melnik V.V. Golodov M.A., Zubakov I.N., Zhukov S.S Technological schemes of mining by cells with widening and backfilling open areas. Izvestiya tulskogo gosudarstvennogo universiteta. Nauki o zemle, 2011, no. 2, pp. 203-206. In Rus.

11. Golik V.I., Burdzieva O.G. Increase of work safety by enlargement of field of application of hardening mixtures from processing waste. Occupational Safety in Industry, 2016, no. 8, pp. 45-50. In Rus. 
12. Herbut A., Khairutdinov M.M., Kongar-Syuryun C., Rybak J. The surface wave attenuation as the effect of vibratory compaction of building embankments. World Multidisciplinary Earth Sciences Symposium (WMESS 2019). Prague, IOP Conference Series: Earth and Environmental Science, 2019. Vol. 362, 012131. DOI: 10.1088/1755-1315/362/1/012131.

13. Dobrzycki P., Kongar-Syuryun Ch., Khairutdinov A. Vibration reduction techniques for Rapid Impulse Compaction (RIC). Modelling and Methods of Structural Analysis. Moscow, Journal of Physics: Conference Series, 2019, vol. 1425, 012202. DOI: 10.1088/1742-6596/1425/1/01220.

14. Herbut A., Rybak J., Brząkała W. On a sensor placement methodology for monitoring the vibrations of horizontally excited ground. Sensors, 2020, no. 20 (7), 1938. DOI: 10.3390/s20071938.

15. Wyjadłowski M. Methodology of dynamic monitoring of structures in the vicinity of hydrotechnical works - selected case studies. Studia. Geotechnica et Mechanica, 2017, vol. 39, no. 4, pp. 121-129. DOI: 10.1515/sgem-2017-0042.

16. Herbut A., Rybak J. Guidelines and recommendations for vibration control in the case of rapid impulse compaction. Advances and trends in engineering sciences and technologies II. High Tatras, CRC Press, Taylor \& Francis Group, 2017. pp. 761-766. DOI $10.1201 / 9781315393827-129$

17. Ermolovich E.A. Cementless filling mix based on technological waste. Belgorod State University Scientific Bulletin: Naturalsciences, 2010, no. 9 (80), pp. 156-158. In Rus.

18. Votyakov M.V. Povyshenie polnoty izvlecheniya zapasov kaliinykh rud na osnove zakladki vyrabotannogo prostranstva galitovykh otkhodov. Dis. Kand. nauk [Increasing the completeness of the extraction of potash ore reserves based on the backfilling of the mined-out space of halite waste. Cand. Diss.]. Moscow, 2009. 89 p

19. Garkushin P.K. Issledovanie $i$ vybor sostavov tverdeyushchey zakladki dlya kaliinykh rudnikov Prikarpat'ya. Diss. Kand. nauk [Research and selection of compositions of hardening backfill for potash mines of the Carpathian region. Cand. Diss.]. Leningrad, 1972. $179 \mathrm{p}$.

20. Kravchenko Yu.G. Razrabotka sostavov tverdeyushchikh zakladochnykh smesei iz otkhodov pererabotki rud kaliinykh predpriyatii. Dis. Kand. nauk [Development of compositions of hardening filling mixtures from ore processing waste from potash enterprises. Cand. Diss.]. Perm, 1985. 122 p.

21. Pengqiang Sh., Xianxiao X., Boyun L. Discussion on the main potash-concentrated districts and the resource potential in China. Geology of Chemical Minerals, 2011, vol. 33, no. 1, pp. 1-8.
22. Khairutdinov M.M., Votyakov M.V. Vybor khimicheskikh dobavok dlya tverdeyushchey zakladki na kaliinykh rudnikakh [Choice of chemical additives for cemented backfill in potash mines]. Mining Information and Analytical Bulletin, 2007, no. 6, pp. 218-221.

23. Niemiec D., Duraj M., Cheng X., Marschalko M., Kubáć J. Selected black-coal mine waste dumps in the Ostrava Karviná region: an analysis of their potential use. World Multidisciplinary Earth Sciences Symposium (WMESS 2017). Prague, IOP Conference Series: Earth Environmental Science, 2017. Vol. 95, 042061. DOI: 10.1088/1755-1315/95/4/042061.

24. Ermolovich E.A., Ermolovich O.V. The study of rheological characteristics of stowing hydromix of «Combinat KMARUDA» ferruginous quartzites tailings. Belgorod State University Scientific Bulletin: Naturalsciences, 2015, no. 9 (206), pp. 143-146. In Rus.

25. Metodicheskie rekomendatsii po kontrolyu kachestva zakladochnykh smesei [Methodical recommendations for quality control of backfill mixtures]. Ed. by N.N. Melnikov. Apatity, Mining Institute of Science of the Federal Research Center «Kola Science Center» (MI KSC RAS), 1990. $94 \mathrm{p}$.

26. Brząkała W. Strength modelling of geomaterials with random systems of structural joints. Probabilistic Engineering Mechanics, 2011, vol. 26, no. 2, pp. 321-330.

27. Votyakov M.V. Formirovanie vysokoprochnogo zakladochnogo massiva pri ispolzovanii $\mathrm{v}$ kachestve aktivatora lignosulfonata [Formation of a high-strength fill mass when using lignosulfonate as an activator]. Mining Information and Analytical Bulletin, 2008, no. 10, pp. 199-203.

28. Gorska K., Muszyński Z., Rybak J. Displacement monitoring and sensitivity analysis in the observational method. Studia Geotechnica et Mechanica, 2013, vol. 35, no. 3, pp. 25-43.

29. Bauer J., Puła W., Wyjadłowski M. Effect of partial mining of shaft protection pillar in terms of reliability index. Georisk, 2015, vol. 9, no. 4, pp. 242-249.

30. Golik V.I., Razorenov Yu.I., Brigida V.S., Burdzieva O.G. Mechanochemical technology of metal mining from enriching tails. Bulletin of the Tomsk Polytechnic University. Geo Assets Engineering, 2020, vol. 331, no. 6, pp. 175-183. In Rus.

Received: 22 September 2020.

\section{Information about the authors}

Marat M. Khayrutdinov, Cand. Sc., National University of Science and Technology MISiS.

Cheynesh B. Kongar-Syuryun, student, National University of Science and Technology MISiS.

Yulia S. Tyulyaeva, student, National University of Science and Technology MISiS.

Albert M Khayrutdinov, student, National University of Science and Technology MISiS. 